(3.8\%) were hospitalized in the field hospital for a duration range of 24 hours to one week. The spectrum of diseases included especially medical illnesses, and only a minority of the patients seen by the IDF field hospital had suffered earthquake-related trauma.

Conclusion: The activities of the field hospital enabled restoration of these abilities in the damaged city.

Keywords: clinic; earthquake; field hospital; illnesses; Israeli Defence Forces; mass casualties; operating theater; Turkey

Prehosp Disast Med 2002;17(s2):s70-71.

E-mail: bardayan@netvision.nct.il

\section{Ambulance Technicians' Indications for Prehospital Interventions}

Hans Okkels Birk, MSc (economics); ${ }^{1}$ Lars Onsberg

Henriksen $^{2}$

1. University of Copenhagen, Institute of Public Health, Department of Health Services Research, and Head of Section, Roskilde County, Department for Health, Denmark

2. Deputy Director, Roskilde County, Department for Health, Denmark

Introduction: Little evidence is available about ambulance personnel's actual indications for use of prehospital interventions. Prehospital interventions increase on-scene time. Little evidence is available on their effect on outcome. In this study, ambulance technicians' use of prehospital interventions were compared with the patients' symptoms.

Method: Prospective, observational, registry study including 56 ambulance technicians from two ambulance stations in a Danish county and 5,516 cases in which a patient was brought to a hospital in 1998. The ambulance technicians recorded their use of prehospital interventions and their assessments of the patients' circulation and breathing.

Results: Ambulance technicians administered oxygen to 2,630 patients, or $47.3 \%$ of the patients brought to hospital, of whom $1,872(71.2 \%)$ showed no symptoms of impaired breathing. An ECG was performed on 1,237 patients (22.3\%); $584(47.2 \%)$ of these patients showed no symptoms or signs of compromised circulation.

Conclusion: The ambulance technicians' indications for use of prehospital interventions were relatively wide.

Keywords: ambulance personnel; assessments; breathing; circulation; interventions, use of; oxygen; symptoms/signs

Prebosp Disast Med 2002;17(s2):s71.

\section{Health Risks for Volunteer Flood Response Workers} in the Flood Disaster, Germany 2002

Stefan O. Brockmann, ${ }^{1,2}$ A. Manger, ${ }^{2,3}$ G. Klittich; ${ }^{1}$ H. Mueller; ${ }^{4}$ B. Domres, ${ }^{2,5}$ P. Kimmg ${ }^{1}$

1. Baden Wuerttemberg State Health Office, Stuttgart Germany

2. Disaster Research Unit, University Hospital of Tuebingen, Germany

3. Department of Anaesthesiology, University of Tuebingen, Germany

4. Technnisches Hilfswerk (THW), Landesverband BadenWuerttemberg, Stuttgart, Germany

5. Department of Surgery, University of Tuebingen, Germany

Introduction: During and after floods, short-term morbidity is known to increase because of infectious diseases and other reasons such as injury while cleaning or repairing property. This study examined the risk of (infectious) disease after contact with surface water, and the other nega- tive health effects of flood response activities.

Methods: During the recent flood disaster in Germany, we examined the volunteer flood response workers of the German disaster relief organization (Technisches Hilfswerk), using a questionnaire and a stool specimen, which was tested for bacterial, viral, and parasitic pathogens. Of the 205 distributed questionnaires, 129 (62.9\%) were returned. Out of 105 stool samples, 64 (61\%) were submitted within one week, and were examined for salmonella, yersinia, shigella, campylobacter, EHEC, Norwalk-like virus, and parasites.

Results: Of the 129 volunteers, $105(81.4 \%)$ had direct contact with surface water during work. A high percentage of volunteers $(39.5 \%)$ reported health complaints. These included skin problems (14.0\%), "flu-like" symptoms (7.8\%), diarrhea $(5.4 \%)$, fever/chills $(1.6 \%)$, and "others" (24.0\%). Ten (7.9\%) volunteers contacted a physician. Stool examinations showed no pathogens. The risk for developing diarrhea and skin problems was increased (RR $=1.5, p>0.05$, n.s.) for volunteers who worked more than 10 days ( 75 th percentile), and the development of "flu-like" symptoms was significantly increased $(\mathrm{RR}=3.45, p<0.05$, 95\% CI 1.07-11.1).

Conclusions: Infectious gastroenteritis seems to be no major problem during floods in developed countries. However, the risk of other health problems, such as skin irritation and injury should be considered.

Keywords: developed countries; diarrhea; fever; floods; "flu-like" symptoms; gastroenteritis; infectious diseases; morbidity; skin; stool; voluntecrs; workers Prehosp Disast Med 2002;17(s2):s71.

\section{Management of Mass Casualties from Earthquake in China \\ Chai Ke-Sheng; Zang Hong-Qi}

Sanitary Office of Administrative Affairs, Department of the First Military Medical University, Guangzhou, People's Republic of China

Some parts of China are geologically active, as they belong to the Earthquake Zone of the Pacific Rim. Statistics show that in the last 100 years $(1900-2000)$, there were 25 serious earthquakes, which killed $1,200,000$ people. Now we pay special attention to the provision of first aid for the wounded, following the most serious earthquake in the Tong-shan Area of northern China. On 28 July 1976, a formidable earthquake of 7.8 magnitude occurred, killing 242,000 inhabitants, and wounding 164,000. Almost all of the buildings, high and low, in the city were demolished. These buildings included water and electricity supply systems and medical organizations. There were 218 Emergency Medical Support Groups from all over the country with memberships of 19,772 medical practitioners. They received 145,800 wounded persons. Among them, 63,400 were serious, and 29,600 were in critical condition. They required emergency surgery. Ninety-two percent of the wounded were treated with debridement, and others were separated into different categories with different treatment as follows: $3.9 \%$ were treated with laparotomy: $0.13 \%$ required intestinal repair, $0.26 \%$ with splenectomy, $1.5 \%$ with reduction of fractures, $0.2 \%$ with amputation, $0.13 \%$ with laminectomy, and $1.14 \%$ required other operations. 